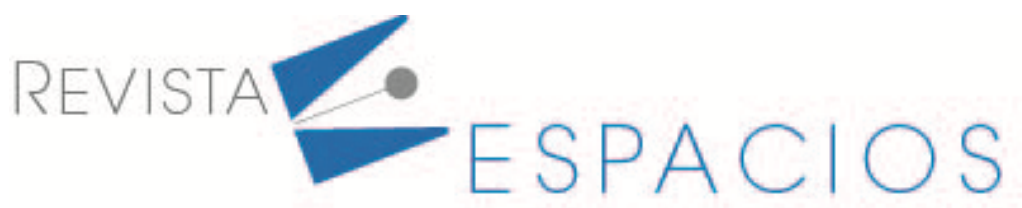

Vol. 42 (08) $2021 \cdot$ Art. 8

Recibido/Received: 03/03/2021 • Aprobado/Approved: 22/03/2021 • Publicado/Published: 30/04/2021

\title{
El periodismo deportivo en el clásico del fútbol español: el reto de informar, sin sesgos, en una sociedad en conflicto
}

\section{Sports journalism in the classic Spanish football: the challenge of reporting, without bias, in a society in conflict}

\author{
ANGULO, Lizandro ${ }^{1}$ \\ MORENO, Antonia ${ }^{2}$ \\ DÍAZ, Norberto ${ }^{3}$
}

\begin{abstract}
Resumen
Esta investigación analiza piezas periodísticas de los diarios Marca y Mundo Deportivo, referidas al clásico español entre el Fútbol Club Barcelona y el Real Madrid, para determinar si existen sesgos informativos, vinculados con el fútbol y los nacionalismos. Se emplea el método del análisis de contenido a una muestra temporal de 15 años (temporadas 2003 a 2018). Se concluye que el reporte deportivo de este evento aumenta la polarización política, por lo que se deben activar protocolos éticos periodísticos.

Palabras clave: periodismo, fútbol, conflicto, España.
\end{abstract}

\begin{abstract}
This investigation analyzes journalistic pieces from the newspapers Marca and Mundo Deportivo, referring to the Spanish classic between Fútbol Club Barcelona and Real Madrid, to determine if there are information biases, linked to football and nationalisms. The content analysis method is used for a 15-year time sample (2003 to 2018 seasons). It is concluded that the sports report of this event increases political polarization, so journalistic ethical protocols must be activated.

Key words: journalism, soccer, conflict, Spain.
\end{abstract}

\section{Introducción}

El fútbol permite proyectar las viejas renciñas entre regiones y países, las heridas de las guerras y los viejos resentimiento en un estadio. Al final de la disputa, todo queda reducido a un resultado de un juego -que cada día se convierte en una actividad más racional y pasional que lúdica-, a la anécdota del triunfo y la derrota depotiva. Pero, ¿es posible que un partido de fútbol siga la trayectoria contraria? Es decir, que el enfrentamiento deportivo exacerbe los ánimos políticos, nacionalistas y revanchistas, a tal punto que incremente la agresión física, psicológica y simbólica entre los bandos en liza.

Esta investigación, justamente, se detiene en analizar el tratamiento periodístico que hacen los diarios Marca y Mundo Deportivo, el primero afín al Real Madrid y, el segundo, al Fútbol Club Barcelona, de este clásico o derbi del fútbol español, matizado no sólo por la rivalidad atlética, sino, fundamentalmente, por las desavenencias

\footnotetext{
${ }^{1}$ Profesor asociado. Departamento de Ciencias Sociales y Jurídicas. Universidad del Tolima. Colombia. langulo@ut.edu.co

${ }^{2}$ Investigadora y Proyect Manager en el grupo e-Vida. Facultad de Ingeniería. Universidad de Deusto. España. antonia.moreno@deusto.es

n Profesor. Programa Gestión de la Moda. Unidades Tecnológicas de Santander. Colombia.norbertod@correo.uts.edu.co
} 
políticas e históricas entre Madrid y Cataluña. Para ello, estudia las publicaciones impresas de los dos periódicos el día después del derbi y a lo largo de 15 años de enfrentamientos (temporadas 2003-2004 a la 2017-2018).

\subsection{Comunicación y deporte}

La comunicación y el deporte es un campo de estudio que ha recibido los aportes de la historia, la sociología y los estudios culturales (Pinheiro, 2012) para la delimitación de sus fronteras epistemológicas. Llopis (2016, p. 86) menciona las publicaciones pioneras en el campo, como Media, Sports and Society (1989) y Media Sport (1998), editados por Lawrance Wenner, y Sport, Media, Culture: Global and Local Dimension (2003), editado por Alina Bernstein y Neil Blain.

Kassing et al. (2004), por su parte, subrayan que el deporte se comunica desde la perspectiva del performance atlético y desde la construcción social de la experiencia deportiva. Pero quienes configuran las primeras líneas de investigación de la comunicación y el deporte son Billings y sus colegas (2012). En efecto, esta investigación toma dos de las que ellos proponen: (1) la línea de las fundaciones y comunidades deportivas, especialmente la de la producción de contenidos de los medios de comunicación y sus efectos en las audiencias, y (2) la línea de la identidad en el deporte, particularmente el binomio entre deporte y política.

\subsection{Fundaciones y comunidades deportivas}

Rojas (2011) y Billings (2010) advierten que los contenidos deportivos son los más demandados por la audiencia, los más apetecidos por las corporaciones de medios que buscan la consecución exclusiva de derechos de emisión y los que más han evolucionado en la presentación de formatos novedosos para mostrar el desempeño atlético con la participación de los aficionados, gracias a las herramientas interactivas que provee internet.

El periodismo deportivo, según Rojas (2011, p. 36), tiene unas fortalezas frente a otras especialidades periodísticas, como la universalidad y el desarrollo de un lenguaje propio. La universalidad se manifiesta con la capacidad para trascender a otros ámbitos, como los de la política y la economía, ya que muchos términos son prestados a estas áreas del conocimiento. El lenguaje propio, se expresa por medio de su alto grado de especialización, su afán innovador al crear palabras y significados, así como su acusado retoricismo, lo que le lleva a recurrir de forma asidua a metáforas y otros usos figurados del lenguaje, cruces léxicos o juegos de palabras para elaborar mensajes impactantes.

Las debilidades, entre tanto, las circunscribe al conflicto idiomático, la primacía del espectáculo sobre la información, la incitación a la violencia y la confusión sobre información y opinión. En el conflicto idiomático, se incluyen errores gramaticales, impropiedades léxicas, utilización y abuso de expresiones gastadas, exceso de extranjerismos, la reiteración de formas coloquiales y vulgarismos, la siglación excesiva y estilo fragmentario para acomodar textos a espacios reducidos. En la primacía del espectáculo, destaca el sensacionalismo para crear emociones y escasamente informar y la futbolización de la información deportiva. En la incitación la violencia, ésta se produce por el lenguaje bélico militar en las piezas periodísticas, la exhibición reiterada, casi morbosa, de imágenes violentas para exacerbar los ánimos de los protagonistas y fanáticos de la actividad competitiva y la búsqueda del morbo y la confrontación mediante la inclusión del testimonio polémico, el gesto agresor, el símbolo violento y el cruce de expresiones malsonantes, con el objeto de crear un ambiente tenso y provocador. La confusión entre informar y opinar comporta una hibridación de géneros propiciada por las excesivas licencias que se dan al reportero deportivo para contar emotivamente un evento o suceso deportivo. Esta situación crea 
confusión en el destinatario y una sensación de ambigüedad en el emisor, en el mejor de los casos, y, en el peor, una intención soterrada de éste por tomar partido de un hecho informativo.

En el clásico español entre el Barcelona y el Real Madrid, hay que considerar dos aspectos desde las empresas periodísticas y el ejercicio del periodismo. Uno de ellos es la que esboza Rojas (2015), en el sentido de que a raíz de que la prensa sensacionalista en España no tuvo el auge del que sí ha gozado la prensa de ese tipo en Inglaterra (The Sun o The Dayly Mirror), la prensa temática deportiva ha tomado el relevo de ese tipo de contenidos, a partir de piezas periodísticas que buscan despertar emociones más que informar. El otro tiene que ver con lo expuesto por González (2014), en lo que atañe al ejercicio periodismo en este tipo de encuentros deportivos.

Buena parte de esa "salsa rosa" futbolística se dirime con periodistas y pseudoperiodistas que no esconden su afinidad por uno u otro club. De hecho, es precisamente su manifiesta identificación con uno de ellos lo que en ocasiones centra el espectáculo mediático en torno al RMCF y al FCB. Se ha perdido buena parte de la asepsia informativa y profesionalismo que caracterizaba el periodismo de antaño cuando se trataba de abordar cuestiones futbolísticas

domésticas. Hoy existe una clara división, eje periodístico entre Madrid (la caverna mediática, la central lechera) y Barcelona (prensa afín, medios al servicio del club), en lo que en ocasiones se ha denominado periodismo deportivo de trincheras (p. 349).

\subsection{Deporte e identidad: la política en la configuración de los nacionalismos}

El deporte está lleno de signos que connotan política, desde la entonación de un himno hasta la presentación de una revista militar, pasando por la presencia misma de políticos en el escenario de la competencia. Resulta curioso, no obstante, que muchos hinchas vean estos actos y estas presencias como un inocuo protocolo, sin atisbar que en el fondo se esconden poderosas estructuras económicas, políticas y culturales. Un concepto que nos permite conocer el estrecho vínculo entre el deporte y la política es el de la ideología. La ideología en tanto agrupa un conjunto de ideas dominantes, valores, rituales e historia de un grupo, tiene la capacidad de ejercer el control, bien sea de forma explícita a través de las instituciones gubernamentales o de manera implícita mediante, por supuesto, el deporte.

En el prólogo de Josep Ramoneda en el libro Los cuerpos del poder: deporte, política y cultura, de la autoría de Orfeo Suárez (2015), se dice que no hay nada más mentiroso que negar la presencia de la política en el deporte:

Si hay una cuestión en la que todos los regímenes políticos, cualquiera que sea su fundamento y su ideología, están de acuerdo es en la utilidad política del deporte. Si hay una estupidez que todos los profesionales e ideólogos del deporte repiten con cinismo -y algunas veces con ignorancia- es que el deporte es algo totalmente ajeno a la política y que debe mantenerse al margen de la misma (pág. 9).

A juicio de González (2014), el deporte genera creencias, imágenes e identidades colectivas alrededor de la nación, las cuales no suelen estar estructuradas en el orden político, pero sí tienen carácter doctrinario para la gran cantidad de personas que siguen los acontecimientos de esta naturaleza. Aun así, los dirigentes políticos, ya empotrados en sus cargos, acostumbran a invitar a campeones del país de distintas disciplinas, con el ánimo de aumentar la popularidad del gobierno o, en su defecto, desviar la atención de los ciudadanos sobre los problemas acuciantes que aquejan a la nación.

Entre tanto, el deporte y la política consienten en la mediación del lenguaje. ¿En qué sentido? En que la política emplea con asiduidad expresiones de los deportes para connotar que en las contiendas existen ataques, defensas, movimientos estratégicos y, finalmente, ganadores y perdedores. Es posible, en consecuencia, que las cuestiones políticas se trivialicen con el uso de las metáforas deportivas, de modo que los ciudadanos vean las acciones de los políticos como un juego. La visión académica también aporta al debate: muchos intelectuales se 
han dado a la tarea de analizar si los giros lingüísticos son solo descripciones o tienen la capacidad de modelar nuestro entendimiento de las cuestiones políticas. Nosotros nos suscribimos más al pensamiento de Billings, Butterworth, \& Turman (2012, pág. 132), cuando señalan que "aun la comunicación académica ha notado que las metáforas comúnmente trabajan en un nivel más profundo, con capacidad para influir en cómo nosotros vemos el mundo".

Uno de los objetivos de la política es, sin duda, el de cultivar y mantener la identidad nacional. El deporte puede ayudar al logro de ese propósito, en la medida en que esta faceta humana se puede convertir en un símbolo idealizado de una identidad colectiva. Los estudiosos de la comunicación se han sentido atraídos por indagar la relación del deporte con la nación y el nacionalismo. En efecto, algunos de ellos manifiestan que en muchas ocasiones la identidad nacional es un producto del deporte que se transmite por los media:

Una razón primaria para esto es que cuando un evento deportivo tiene un atractivo nacional, conduce/lleva a altos índices de sintonía en televisión. En consecuencia, cuando los estudios de comunicación examinan la relación entre deporte y nacionalismo, ellos a menudo lo hacen mediante el estudio de los medios de comunicación (Billings, Butterworth,

\section{\& Turman, 2012, pág. 134).}

Por supuesto, el deporte contribuye a la construcción del concepto de patria, en tanto entrenamiento militar, preparación para el trabajo o como orgullo nacional. Sin embargo, hay que preguntarse hasta qué punto tiene la capacidad de una nacionalización política. Lo que sí no cabe duda es que el deporte, como fenómeno social, posee el poder de adscripción identitaria, gracias a su carácter cultural (los símbolos de la identidad deportiva), emocional (las adhesiones y desafecciones que generan las pasiones deportivas) y mediático (la identidad narrada y transmitida por los medios de comunicación) (González, 2014).

El fomento de la unidad nacional puede ser una estrategia que logre algunos fines. Eleva la autoestima de los ciudadanos al valorar todo el acervo cultural de la comunidad, pero se corre el riesgo de cultivar una actitud nacionalista que estereotipe o denigre de otros y de sus respectivas identidades. Por eso, las narraciones deportivas deben ser precavidas al sobredimensionar las historias del "nosotros contra ellos" en las que no predomina la habilidad atlética, sino lo que los rivales representan como colectividad, porque pueden influir negativamente en las posturas políticas de algunas personas hacia otros pueblos. La discriminación, los prejuicios, las ofensas y la agresión pueden ser sus consecuencias más nefastas.

Otra arista es el vínculo entre el deporte y la resistencia de los pueblos. En efecto, el poder está explícito e implícito en cualquier sistema político, incluido en el democrático. El poder se puede definir como la disposición -legítima o no- de un sujeto para decidir sobre el acceso, la oportunidad y los recursos. Y como existen personas que no tienen el poder, sino que, por el contrario, están al margen o discriminados por él, asumen una posición de resistencia. Y dado el carácter público y popular del deporte, éste puede llegar a ser una tribuna eficiente, eficaz y efectiva para comprometer una ferviente lucha política y para lograr el cambio social positivo.

El caso del fútbol es paradigmático, debido a su capacidad simbólica de hermanar y, al mismo tiempo, de separar a los grupos de pertenencia. Según González (2014), el balompié relaciona a personas con orígenes socioculturales diversos, une al rey y al vasallo, pero reagrupa a los sujetos en espacios simbólicos de identidad nosotros y otros. El autor agrega que las emociones que genera el fútbol suelen ser parecidas a los nacionalismos de masas:

(...) si algo caracteriza al nacionalismo de masas es la carga emocional que las personas invierten en la causa para defender sus símbolos y creencias. Y si algo caracteriza al deporte en general y al fútbol en particular es la inversión emocional, la pasión, que aficionados y no tan aficionados expresan ya sea en los propios terrenos de juego o a través del consumo 
habitual de diarios deportivos, los cuales tampoco escatiman esfuerzos en exaltar esos

sentimientos (p. 345).

El papel de los medios de comunicación para motivar este proceso es muy relevante. En efecto, el futbol crea identidad simbólica y emocional más que otras disciplinas, gracias al poder que tienen los medios de comunicación como transmisores de las formas simbólicas asociadas a este deporte. Los medios, en este contexto, actúan no sólo como difusores de esta actividad competitiva, sino también como agentes que recrean, reinterpretan y actualizan la identidad, ajustándola a las transformaciones percibidas.

En el caso del clásico español, ser del Real Madrid Club de Fútbol o del Fútbol Club Barcelona tiene connotaciones identitarias más allá de un seguimiento efusivo de un equipo o de unos jugadores. Prácticamente, se convierte en una filosofía, una tradición cultural que se ha configurado desde el mismo nacimiento de los equipos y desde la afinidad de éstos con las ideologías y gobiernos de turno.

El Barcelona ha sido el estandarte de la independencia catalana, de ahí que desde el crisol de la identidad se conciba como "más que un club". Esa frase refleja las aspiraciones de una parte de los catalanes de constituirse como nación, de modo que los triunfos del equipo se convierten en victorias políticas, mientras que las derrotas se asociación a la frustración de sus gentes de no poder (no querer, agregamos nosotros) o saber articularse al Estado español (Colomé, 1999). Este hecho comenzó a notarse más claramente a mediados de los setenta, con el ocaso del franquismo, el regreso del presidente catalán en el exilo Josep Tarradella. Igualmente, importantes son otras dos épocas, en las que el equipo catalán revitaliza ese papel sociopolítico: en los 90, con la llegada de triunfos deportivos significativos y globales como los del llamado dream team (dirigido por el holandés Johan Cruyff) y en el siglo XXI con el Pep Team (en honor a su técnico y exjugador blaugrana Pep Guardiola).

Por su parte, el RMCF gracias a sus logros deportivos en las Copas de Europa de finales de la década de los 50, se catapultó en el mejor embajador deportivo de Franco en el exterior, por encima de otros héroes deportivos como Bahamontes en el ciclismo y Santana en el tenis. De manera que la utilización del club de la capital de España por la propaganda franquista lo etiquetó como "el equipo del régimen", símbolo de una España grande y próspera.

A la fecha, el clásico o derbi del fútbol español es considerado el partido entre clubes más esperado y seguido en el planeta. De hecho, las mediciones recientes aseguran que cuenta con una audiencia de unos 650 millones de espectadores en 180 países -14 millones de ellos corresponde a espectadores españoles-, más alta que las del Super Bowl y las finales de la Champions (Leone, 2019).

\section{Metodología}

Esta investigación emplea un enfoque cuantitativo, no experimental, con alcance descriptivo. En palabras de Hernández, Fernández y Baptista (2014) y Scutt (2019), el enfoque cuantitativo persigue medir variables con precisión y objetividad, como lo sugiere el paradigma positivista. En este caso, la investigación tiene un alcance descriptivo, en tanto que busca conocer las propiedades del objeto de estudio, detallar sus características y medir variables de manera independiente. El método es el análisis de contenido aplicado a una muestra representativa de los periódicos Marca y Mundo Deportivo, ambos de España.

\subsection{Análisis de contenido}

El análisis de contenido es un método que descifra, interpreta y comprende la estructura e impacto de los mensajes, mediante la exposición de variables cuantificables. Como lo señala Igartua, se constituye en una técnica de investigación que descubre el ADN de los mensajes mediáticos, a fin de reconstruir su estructura, componentes, arquitectura y funcionamiento interno (Igartua, 2006). Otras de sus características son su objetividad y sistematicidad. Objetividad o intersubjetividad, puesto que se deberían derivar resultados similares en una replicación del estudio; sistemático, en tanto que su desarrollo depende de un conjunto de reglas (Bryman 
\& Teevan, 2005; Wimmer \& Dominick, 1996), como el sistema de categorías con sus definiciones constitutivas y operativas.

Los pasos para su aplicación, según McQuail (2000, p. 423), son: (1) identificar universos y muestras de contenidos y sus temporalidades; (2) establecer un sistema de categorías, amparado en la revisión exhaustiva de la teoría y conceptualizaciones en torno al objeto de estudio; (3) escoger una unidad de análisis; (4) comparar el contenido con el sistema de categorías y (5) expresar los resultados, en función de la frecuencia de ocurrencia de los referentes buscados.

En los medios de comunicación, el análisis de contenido se sustenta en la teoría de la agenda setting y, en su derivada, la teoría del framing. La teoría de la agenda setting sugiere que los medios de comunicación tienden a centrarse sobre unos problemas en detrimento de otros al momento de informar (Igartua \& Humanes, 2010).

Con base en esta idea, los autores agregan que:

La gente reacciona ante las noticias de una manera básica: pensando que los acontecimientos que más cobertura reciben son los más importantes. Desde esta perspectiva, los medios ejercen una influencia cognitiva poderosa porque hacen creer a la gente que ciertas cosas (sucesos, temas, personas) son importantes mientras que otras no lo son tanto. En este sentido, se ha indicado que los medios son más efectivos en decir a la gente sobre qué es más importante pensar que en decir a la gente qué o cómo pensar (2010, pág. 244).

Para MacQuail, la agenda setting supone un proceso de influencia, de prioridades de grupos de presión económicos, políticos, a las prioridades de los media, "en las que tienen un gran peso los valores informativos y los intereses de las audiencias, y de ahí a las opiniones del público" (2000, p. 536)

La teoría del framing, entre tanto, se constituye en el segundo nivel de la agenda setting, de acuerdo con Igartua y Humanes (2010). La diferencia entre la agenda setting y el frame radica en que la primera selecciona los temas de la agenda y los jerarquiza, mientras que el segundo decide cuál será el foco principal de la historia, el encuadre fundamental, el ángulo determinado, la perspectiva concreta o la idea organizadora central. Así las cosas, los frames (encuadres) remiten al tratamiento que se da al acontecimiento relatado en la noticia u otro género periodístico. Con esta explicación, se piensa que los encuadres no son resultado del azar, sino de un conjunto de normas explícitas e implícitas con las que el comunicador elabora el mensaje.

La selección, enfoque y, a veces, imposición de los temas que se han de publicar en los medios de comunicación sólo es evidente a través del análisis de contenidos, pues no sólo identifica esos contenidos, sino también su frecuencia y tendencia con datos numéricos, con lo cual se infieren cambios en la opinión pública y en las posturas editoriales de la prensa (McQuail, 2000). Se parte del hecho de que son los medios de comunicación una fuente, aunque no la única, de la información que recibimos y con la que se construyen los esquemas mentales y se configura la opinión pública, es decir, crean agenda y, con frecuencia, un ángulo determinado del hecho noticioso (Rubio, 2009).

La pertinencia de este método para esta investigación, estriba, justamente, en que identifica y cuantifica los mensajes periodísticos sobre el clásico del fútbol español (Real Madrid vs Barcelona), y ofrece una perspectiva más objetiva sobre ellos. Adicionalmente, permite conocer la estructura del contenido en las piezas periodísticas, sus componentes, funcionamiento, y encuadre. 


\subsection{Universo y muestra de medios}

España cuenta con siete periódicos deportivos en papel e internet, concentrados especialmente en Madrid, Barcelona y la Comunidad Valenciana (Kiosco.net, 2016), lo cual constituye su universo de medios. Para efectos de esta investigación, se seleccionaron dos: Marca, diario de la capital de España reconocido por su afinidad al Real Madrid, y Mundo Deportivo, diario de la capital catalana, afín al equipo Barcelona. Ambos periódicos son escogidos, además, porque son de circulación nacional y, principalmente, porque representan el enfrentamiento clásico entre los dos clubes, cuyas sedes se localizan en la Comunidad Autónoma de Madrid y la Comunidad Autónoma de Cataluña, divididas políticamente por encuentros y desencuentros históricos.

\subsection{Universo y muestra de contenidos}

En los dos periódicos, se informa de fútbol de y otros deportes. En el caso de este estudio, se tendrá en cuenta muestras de informaciones relacionadas con el resultado de los clásicos entre Real Madrid y Barcelona, es decir, las notas de prensa publicadas en papel el día después de este tipo de encuentros, pues allí es evidente conocer cómo sus periodistas reportan ese hecho en función de las emociones producidas por la victoria o la derrota.

\subsection{Universo y muestra temporal}

En España, desde el año 2003 hasta el 2018, periodo en que se concentran 28 derbis propios de la liga (no de otras competiciones como Copa del Rey o Champions), entre el Real Madrid y el Barcelona. Se toma este periodo como referencia, en tanto que es muy estrecha la rivalidad entre los dos equipos y sus aficiones, y porque confluyen manifestaciones separatistas de la comunidad autónoma de Cataluña. La muestra temporal corresponde a los resultados de los clásicos entre el Real Madrid y el Barcelona, publicados el día después de los mismos por Marca y Mundo Deportivo, así:

\section{Cuadro 1}

Fechas de la publicación impresa de los periódicos Mundo Deportivo y Marca de los resultados del clásico del fútbol entre el Real Madrid y el Barcelona

Fechas de publicación en Marca y Mundo Deportivo

de diciembre de 2003; 26 de abril de 2004; 21 de noviembre de 2004; 11 de abril de 2005; 20 de noviembre de 2005; 2 de abril de 2006; 23 de octubre de 2006; 11 de marzo de 2007; 24 de diciembre de 2007; 8 de mayo de 2008; 14 de diciembre de

2008; 3 de mayo de 2009; 30 de noviembre de 2010; 17 de abril de 2011; 11 de diciembre 2011; 22 de abril de 2012; 8 de octubre de 2012; 4 de marzo de 2013; 27 de octubre de 2013; 24 de marzo de 2014; 26 de octubre de 2014; 22 de marzo de 2015; de noviembre de 2015; 3 de abril de 2016; 4 de diciembre de 2016; 24 de abril de 2017; 24 de diciembre de 2017 y 7 de junio de 2018.

TOTAL: 28 partidos

Fuente: Mundo Deportivo y Marca (2003-2018)

\subsection{Unidad de análisis}

Se refiere al elemento o ítem de contenido que se analiza como unidad y se registra en la base de datos. Las unidades de análisis utilizadas son las siguientes.

Unidad de análisis de las piezas periodísticas: la unidad de análisis es la totalidad de la pieza periodística referida al clásico del fútbol español, de manera que cada una de ellas es una unidad o ítem.

Unidad de análisis de los componentes de las piezas periodísticas: la unidad de análisis son los componentes de las unidades periodísticas, como tipo de titular, género y lenguaje periodístico, fotografía, infografía y enfoque de la pieza periodística, los cuales se codifican con base en un sistema de categorías. 
Unidad de análisis de las fuentes de las piezas periodísticas: la unidad de análisis de las fuentes es cada una de las personas o instituciones que dan declaraciones textuales sobre el clásico del fútbol español, de modo que cada fuente y su testimonio son unidades por separado que se evalúan en sí mismas, de acuerdo con el sistema de categorías.

\subsection{Planos de análisis}

Se contemplan dos planos de análisis: El primero, referido a cuestiones periodísticas, a saber: titular, género periodístico, lenguaje, enfoque, fotografía, infografía; el segundo, versado sobre el valor del testimonio de cada fuente (persona o institución), en el marco de la línea de investigación del deporte y la identidad, cuyas definiciones se encuentran en el sistema de categorías.

\subsection{Prueba de validez y fiabilidad intercodificadora}

Siguiendo con los criterios estrictos del análisis de contenidos, se lleva a cabo un test de fiabilidad intercodificadora, consistente en que varios codificadores independientes codifican una muestra del contenido de prensa temática española y generalista de Colombia para que haya consistencia y coherencia científicas. Para ello, se empleó la fórmula de fiabilidad de Holsti (1969). Fiabilidad=3M / (N1 + N2 + N3), donde M es el número de decisiones codificadoras en las que coinciden los codificadores (en este caso tres) y $\mathrm{N}$ el número de codificaciones realizadas por cada uno de ellos. N1 es el autor y N2 y N3 son dos codificadores independientes.

En esta investigación, la prueba de fiabilidad intercodificadora obtuvo un resultado del 0,91\%. De acuerdo con la literatura internacional, se considera que, si existe una coincidencia igual o superior al $90 \%$, las definiciones operativas y el proceso codificador son fiables.

\section{Resultados y discusión}

Los resultados y discusión se expresan en las siguientes ilustraciones y cuadros, con su respectivo análisis.

Figura 1

Resultados del clásico del fútbol español entre las temporadas 2003-2004 y 2017-2018

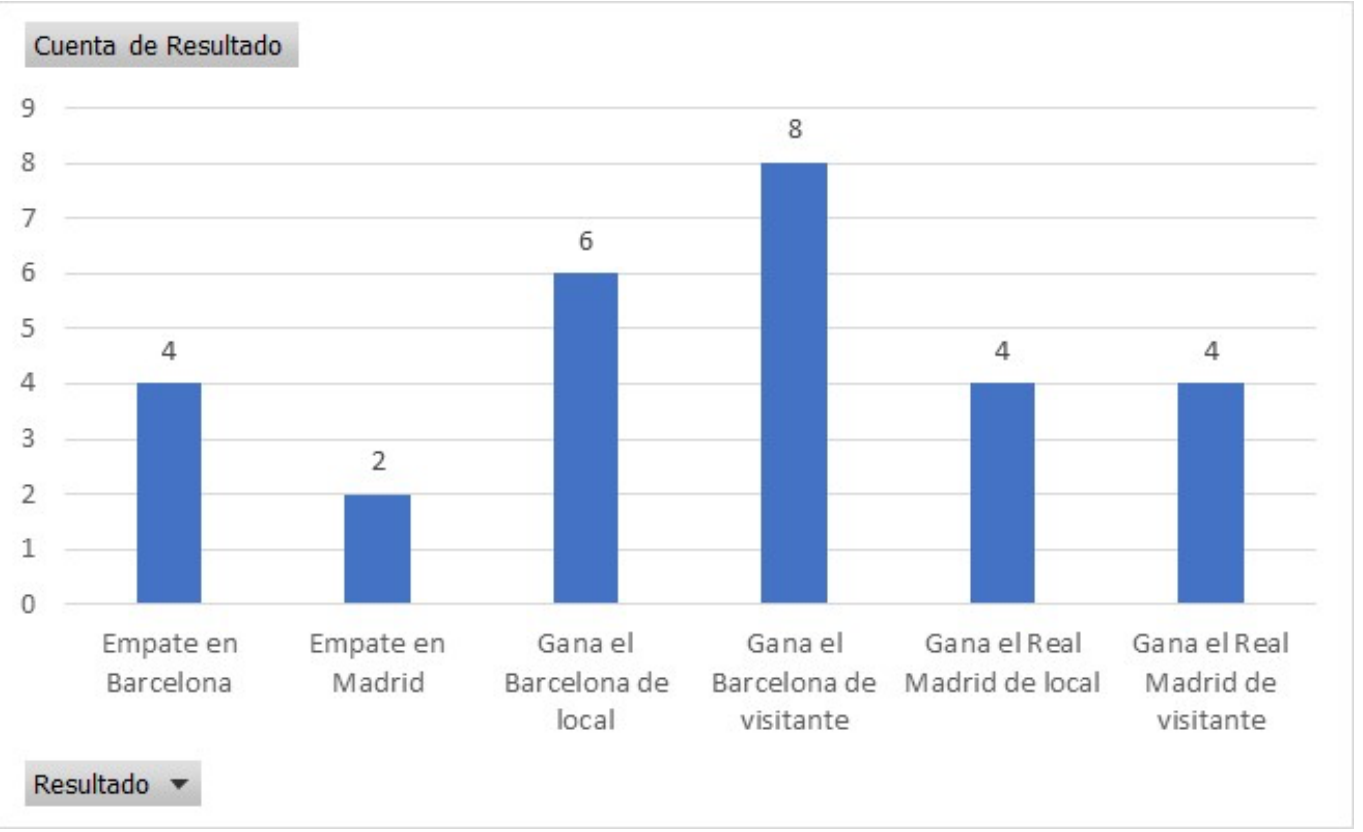

Fuente: elaboración propia 
Los clásicos entre la temporada 2003-2004 y la temporada 2017-2018 se caracterizan por un mejor desempeño del Fútbol Club Barcelona sobre el Real Madrid. Por ejemplo, el Barcelona ganó 8 encuentros de visitante al Madrid y 5 de local, frente a 4 triunfos del Real Madrid sobre el Barcelona de visitante e igual número de local. El año 2003 del mes de noviembre coincide con el debut de Messi en el equipo bul grana. Cristiano Ronaldo lo hizo en el 2009 en el Real Madrid.

\section{Cuadro 2}

Número de piezas periodísticas sobre el clásico del fútbol español en Marca y Mundo Deportivo desde la temporada 2003-2004 a la temporada 2017-2018

\begin{tabular}{|l|l|l|l|}
\hline Año/temporada & Marca & Mundo Deportivo & Total general \\
\hline 2003 & 8 & 34 & 42 \\
\hline 2004 & 44 & 63 & 107 \\
\hline 2005 & 52 & 57 & 109 \\
\hline 2006 & 52 & 53 & 105 \\
\hline 2007 & 60 & 79 & 139 \\
\hline 2008 & 58 & 67 & 125 \\
\hline 2009 & 69 & 73 & 142 \\
\hline 2010 & 79 & 50 & 129 \\
\hline 2011 & 63 & 73 & 136 \\
\hline 2012 & 62 & 59 & 121 \\
\hline 2013 & 64 & 62 & 126 \\
\hline 2014 & 54 & 69 & 123 \\
\hline 2015 & 80 & 67 & 147 \\
\hline 2016 & 64 & 68 & 132 \\
\hline 2017 & 53 & 67 & 120 \\
\hline 2018 & 27 & 25 & 52 \\
\hline Total general & 889 & 966 & 1855 \\
\hline & & Fuente: elaboración propia & \\
\hline
\end{tabular}

El periódico Marca ha publicado menos piezas periodísticas sobre el clásico del fútbol español que el periódico Mundo Deportivo. La relación es de 889 (48\%) a 966 (52\%). Sólo en 4 años $(2010,2013,2015,2018)$ ha informado más sobre este acontecimiento deportivo que el Diario Mundo Deportivo. Aunque podría decirse que son más las piezas periodísticas en el 2010, por ejemplo, porque el Real Madrid ganó en los dos encuentros, la realidad es que fue derrotado en las dos oportunidades tanto de visitante como de local. Es factible advertir que Marca, con su carácter más nacional, dedicó más espacio a otros deportes en los que España sobresalió en estos 16 de muestra, como el tenis, fórmula 1 y ciclismo, entre otros. 
Figura 2

Tipo de titular en Mundo

Deportivo y Marca

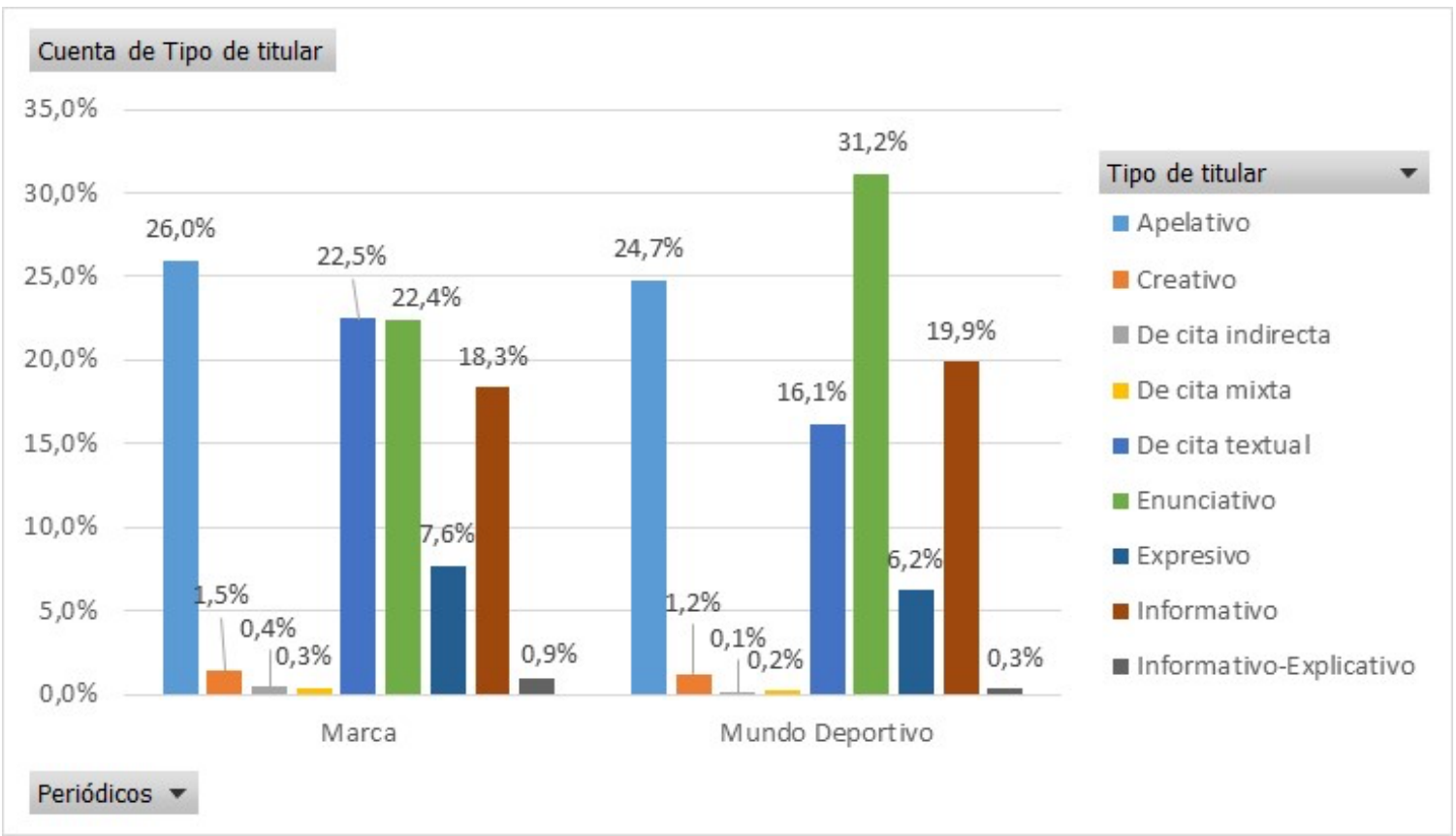

Fuente: elaboración propia

Tanto Marca (26\%) como Mundo Deportivo (24,7\%) utilizan con frecuencia los titulares apelativos, los cuales, según López (2009), buscan crear emociones, llamar la atención, más que informar. Tienen un carácter sensacionalista, requieren un conocimiento contextual del fútbol (en este caso) y no suministran información completa. También, como veremos más adelante, son muy empleados en las crónicas, noticias y columnas de opinión. Por ejemplo, "Neymar se come a Bale", columna titulada por Mundo Deportivo del 27 de octubre de 2013, página 8.

Imagen 1

Titular apelativo en Mundo Deportivo

8 BARCA

$\odot$ Fue decisivo en el duelo ante el galés, un holograma

Neymarse come a Bale
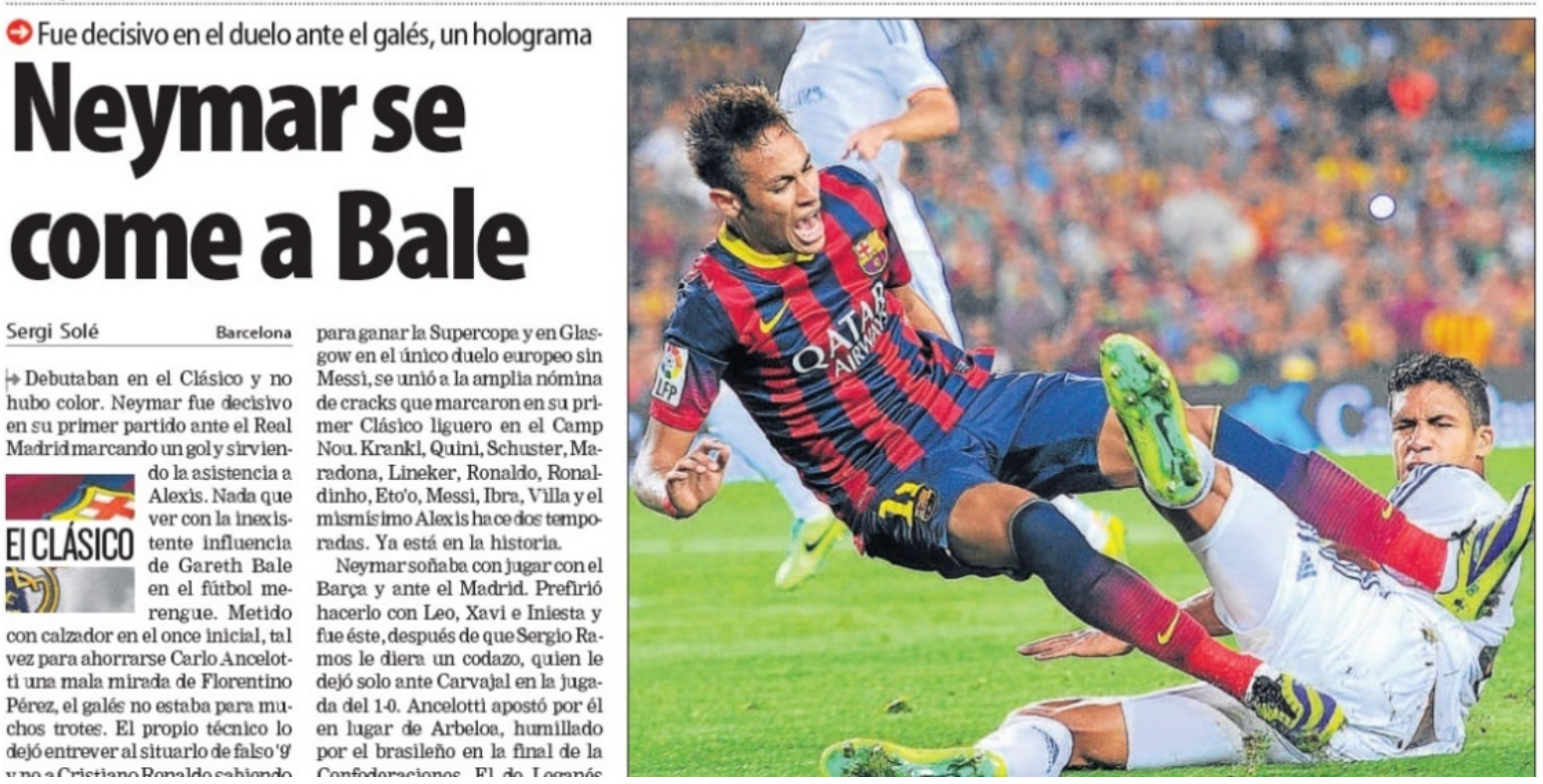
Otros titulares, habituales en los dos diarios, son los enunciativos: Marca $(22,4 \%)$ y un poco más en Mundo Deportivo (31,2\%), los cuales se definen como aquéllos que no revelan todos los datos del acontecimiento deportivo, sino que se refiere a él de una forma lacónica, con pocas palabras. Son pocos los titulares creativos en ambos periódicos.

Figura 3

Género periodístico del clásico del fútbol español en Marca y Mundo Deportivo

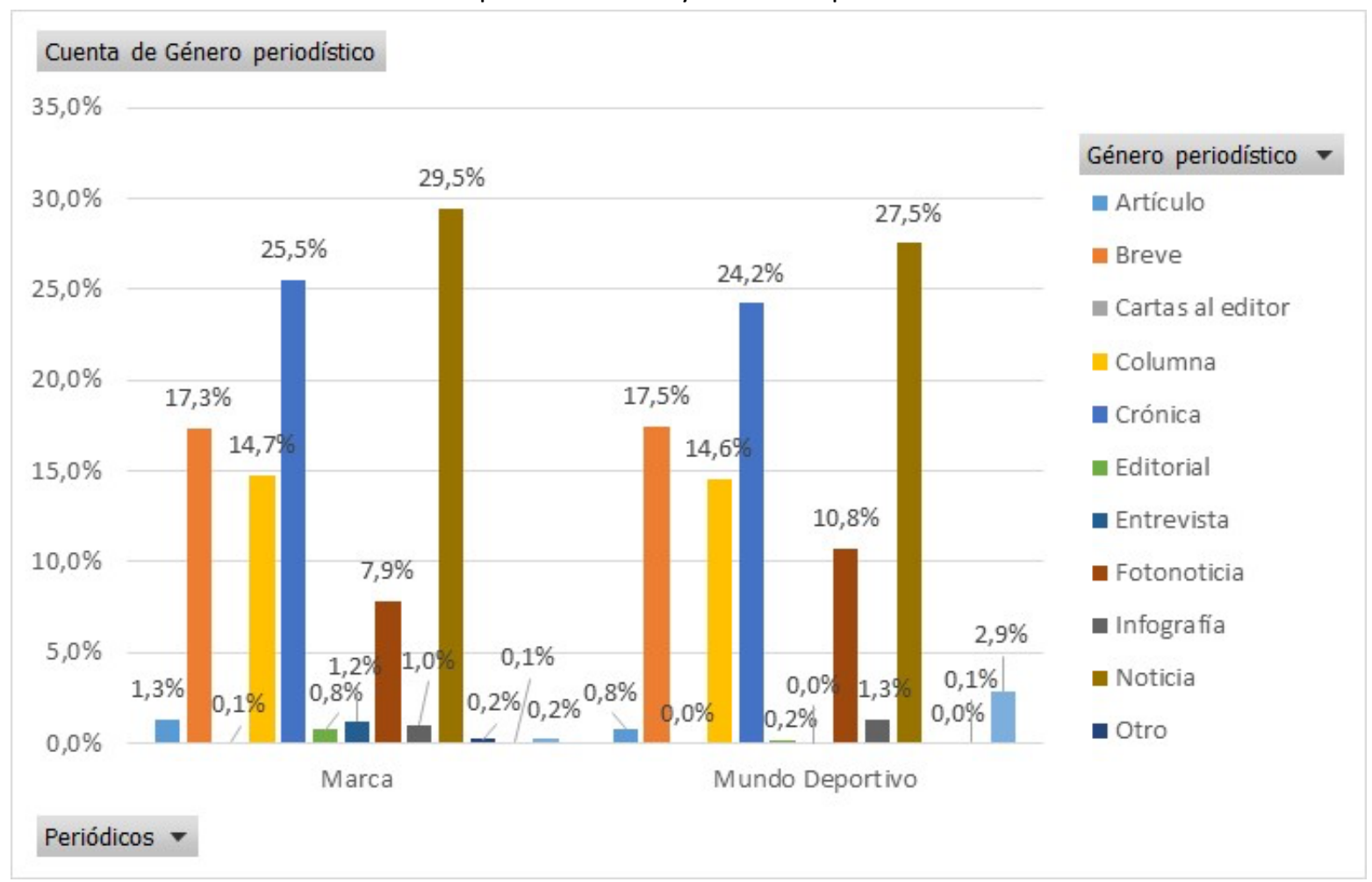

Fuente: elaboración propia

Como lo señala Alcoba (2010), el cubrimiento de los deportes suele hacerse a través de tres géneros periodísticos: la crónica, la columna, aunque en esta investigación agregamos la noticia. Los valores se presentan de manera consistente, similar en los dos diarios: Marca: columna $(14,7 \%)$, crónica $(25,5 \%)$ y noticia $(29,5 \%)$; Mundo Deportivo: columna $(14,6 \%)$, crónica $(24,2 \%)$ y noticia $(27,5 \%)$. La breve se usa con frecuencia en ambos periódicos, aunque su valor informativo es inferior al resto de géneros. Fuente: elaboración propia

El enfoque que predomina es el del fútbol y la competencia, aunque con más incidencia en Mundo Deportivo $(86,9 \%)$ que en Marca (79,5\%). Esta categoría enfatiza en el discurrir de las principales jugadas, la manera como se logran las anotaciones, la descripción del sistema táctico, las determinaciones de los directores técnicos, los resultados y tabla de posiciones. Otra categoría que se destaca en menor proporción es la del fútbol y confrontación, la cual se define como el choque, el cruce de palabras ofensivas, recordatorios de falta de deportividad, agresiones físicas y simbólicas y, algunas veces, alusiones nacionalistas e independentistas. Marca mantiene un enfoque de confrontación más alto (10,2\%) que Mundo Deportivo (4,5\%). Un ejemplo de confrontación, concretamente de falta de deportividad se muestra en Marca del 30 de noviembre de 2009, página 1, con el siguiente título "Tramposos: frieron a láser a CR7 y Pepe". 
Figura 4

Género periodístico del clásico del fútbol español en Marca y Mundo Deportivo

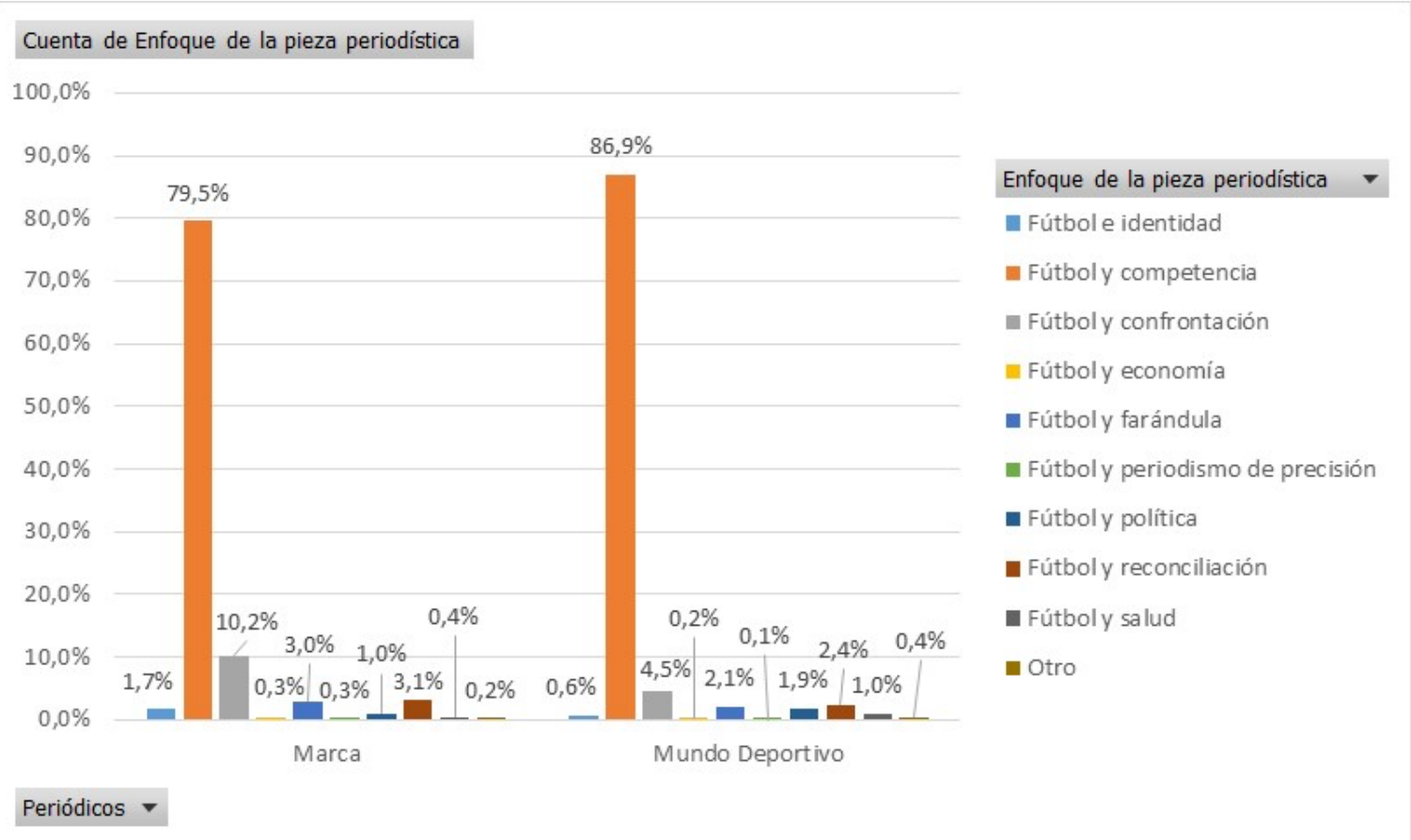

Fuente: Elaboración propia

Imagen 2

Fútbol y confrontación en Marca

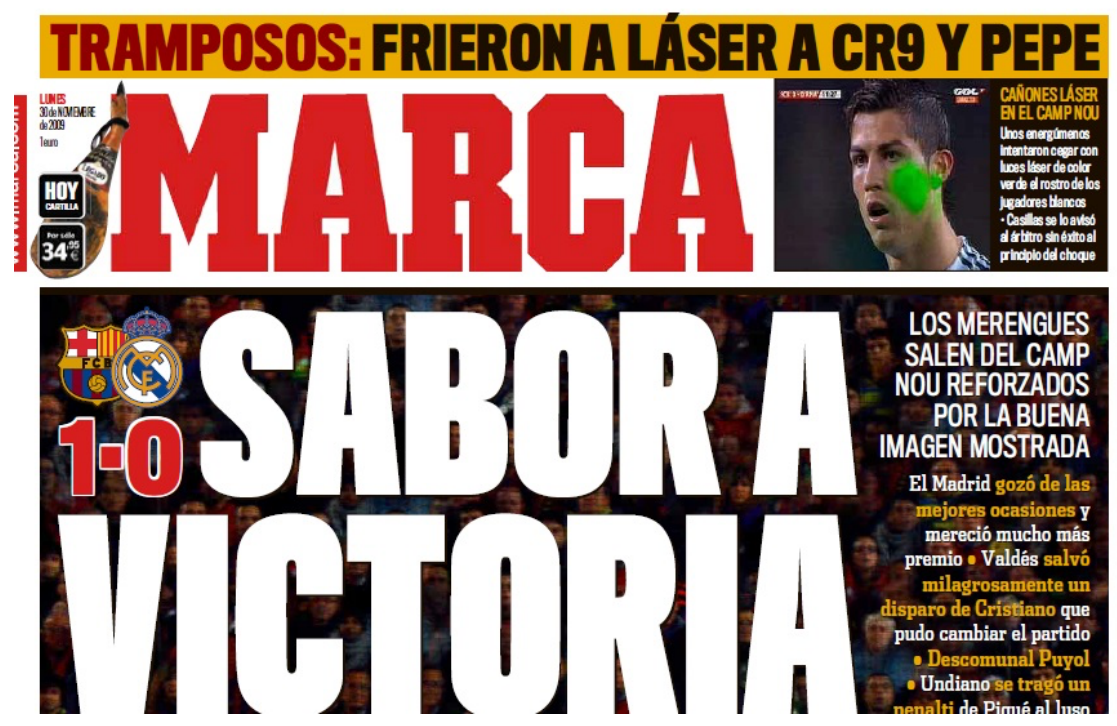

Un ejemplo del enfoque de fútbol y competencia se registra en Mundo Deportivo del 7 de mayo de 2018, página 4, bajo el titular "Esfuerzo heroico del campeón para resistir". 
Imagen 3

Fútbol y competencia

en Mundo Deportivo
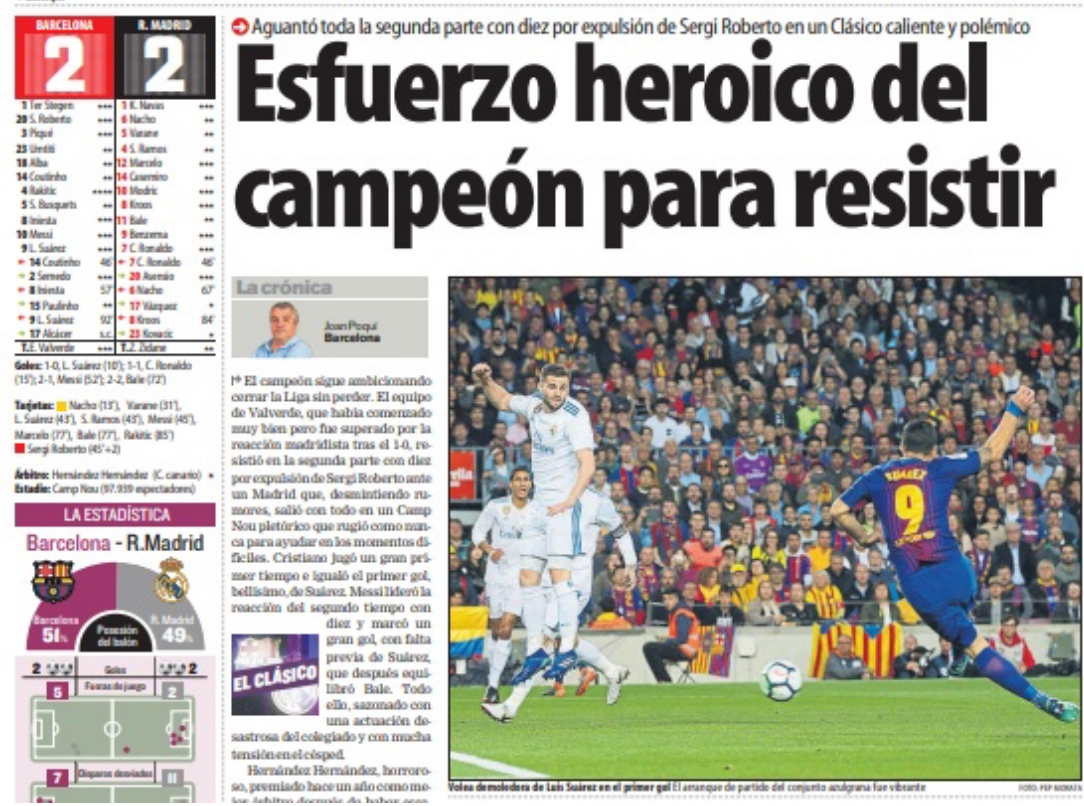

Figura 5

El lenguaje periodístico en los clásicos del fútbol en Marca y Mundo Deportivo

\section{Cuenta de lenguaje periodístico}

$60,0 \%$

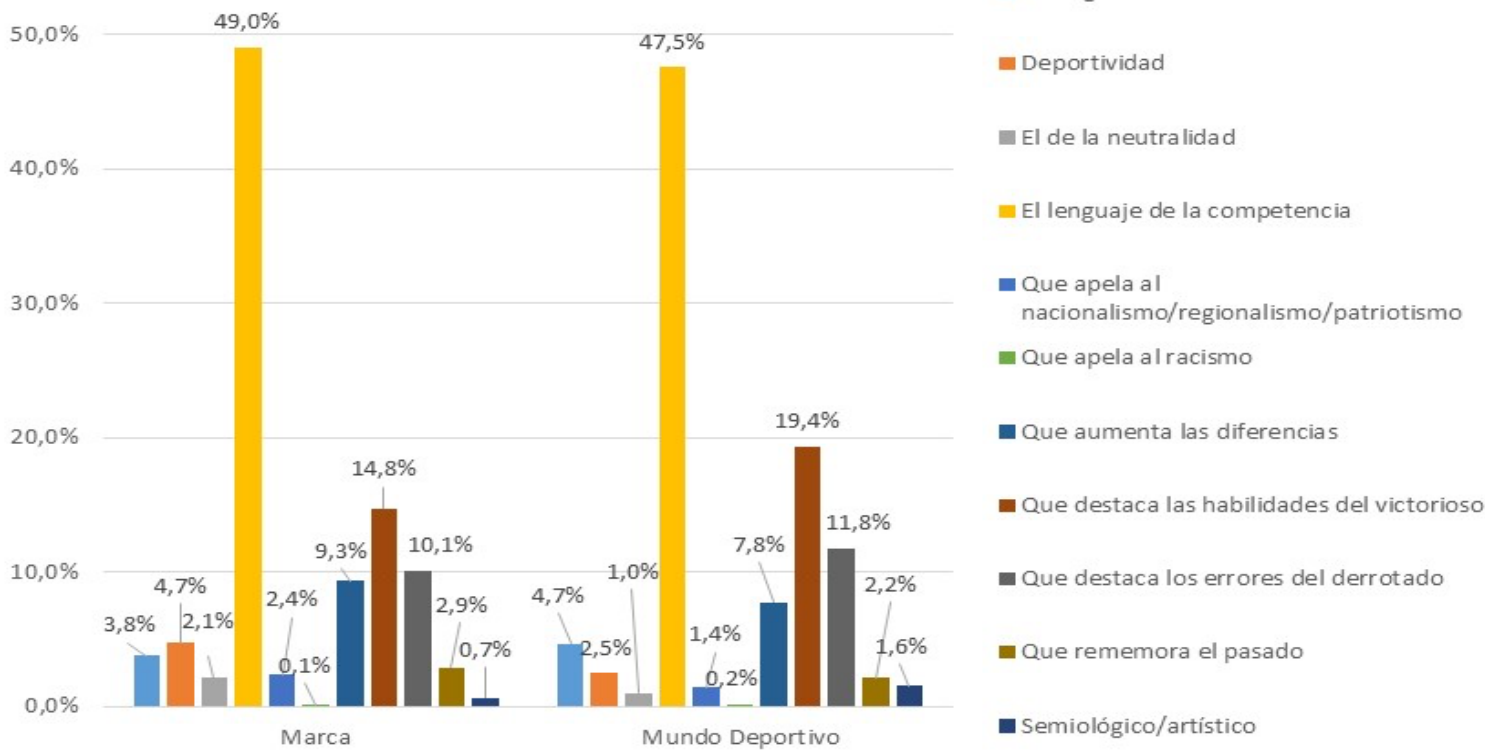


El lenguaje que predomina es el de la competencia: Marca (49\%) y Mundo Deportivo (47,5\%), vinculado con las principales jugadas del cotejo, los sistemas tácticos y las conclusiones de por qué se produjo el resultado final. El lenguaje de la guerra está más presente en Mundo Deportivo $(4,7)$ que en Marca $(3,8 \%)$, aunque en ambos casos los porcentajes son bajos. Un ejemplo del lenguaje de la guerra es el que se utiliza en la pieza periodística titulada "Barça toma Madrid" de Mundo Deportivo del 26 de abril de 2004, página 2, donde existen expresiones como "dinamitó la liga", "el funeral de la famosa galaxia" y "necesitó de banderilla de fuego" con las que se describe el triunfo de visitante del Barcelona sobre el Real Madrid, 2 goles por 1.

El lenguaje de la deportividad está más presente en los dos diarios, pero más en Marca $(4,7 \%)$ que en Mundo Deportivo (2,5\%). Un ejemplo de deportividad, aunque con tono irónico, es el que se reporta en Marca del 8 de octubre de 2012, página 26, con el título “El Camp Nou fue 'independiente'”. Allí se indica que, pese a la crispación política del momento, la mayoría de los aficionados culés estuvieron más pendientes del fútbol que de las consignas a favor de la independencia catalana.

Imagen 4

El lenguaje de la deportividad en Marca

\title{
El Camp Nou fue 'independiente'
}

\begin{abstract}
AFICIÓN Estuvo más pendiente del fútbol que de consignas políticas
\end{abstract}
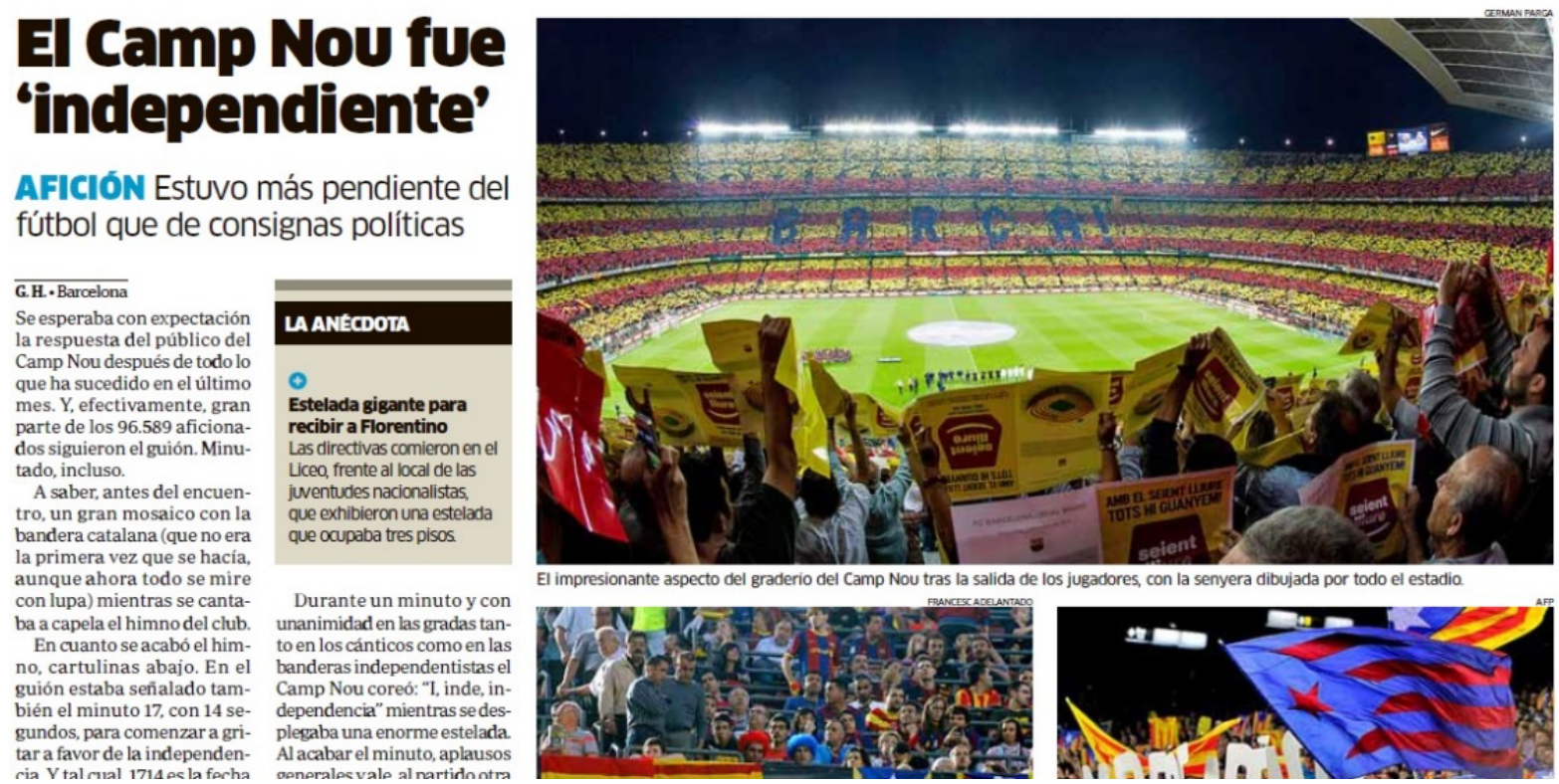

El impresionante aspecto del graderio del Camp Nou tras la salida de los jugadores, con la senyera dibujada por todo el estadio.
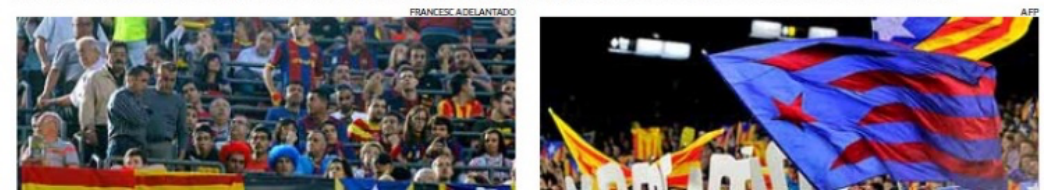

El lenguaje que apela al nacionalismo/regionalismo/patriotismo, con el que se pretende el reforzamiento de las identidades colectivas, apelando a la diferenciación cultural, política, religiosa, es más evidente en Marca $(9,3 \%)$ que en Mundo Deportivo (7,8\%). En este último, aparece una alusión clara y directa a la identidad catalana en la edición del 26 de abril de 2004, página 5, en la columna titulada “¡Para quitarse el sombrero!" En uno de sus párrafos se afirma lo siguiente: "Sabía que puyol tenía que salir como el hombre más destacado, porque el alma del catalán es única, porque lo siente iiy es grande!! Que ahí no hay solo garra, ahí hay calidad”. 
Cuadro 3

La fotografía en el clásico del fútbol español en Marca y Mundo Deportivo

\begin{tabular}{|l|l|l|l|}
\hline & Marca & $\begin{array}{l}\text { Mundo } \\
\text { Deportivo }\end{array}$ & $\begin{array}{l}\text { Total } \\
\text { general }\end{array}$ \\
\hline Caricatura & $0,3 \%$ & $2,2 \%$ & $1,3 \%$ \\
\hline Foto rostro del protagonista & $24,5 \%$ & $33,4 \%$ & $29,2 \%$ \\
\hline $\begin{array}{l}\text { Muestra agresiones de } \\
\text { jugadores/directivos/aficionados } \\
\text { contra el árbitro }\end{array}$ & $0,6 \%$ & $0,2 \%$ & $0,4 \%$ \\
\hline Muestra agresiones entre aficionados & $0,7 \%$ & $0,1 \%$ & $0,4 \%$ \\
\hline Muestra agresiones entre la dirección técnica & $0,1 \%$ & $0,0 \%$ & $0,1 \%$ \\
\hline Muestra agresiones entre los jugadores & $2,1 \%$ & $0,7 \%$ & $1,4 \%$ \\
\hline Muestra incidencias competitivas del partido & $23,0 \%$ & $22,9 \%$ & $22,9 \%$ \\
\hline Muestra los momentos del gol & $3,6 \%$ & $2,0 \%$ & $2,8 \%$ \\
\hline Muestra símbolos patrios & $1,6 \%$ & $1,2 \%$ & $1,4 \%$ \\
\hline No aplica & $0,3 \%$ & $0,4 \%$ & $0,4 \%$ \\
\hline Otra & $0,7 \%$ & $0,7 \%$ & $0,7 \%$ \\
\hline Propone convivencia y reconciliación & $3,7 \%$ & $5,0 \%$ & $4,4 \%$ \\
\hline Rostros derrota/victoria & $10,9 \%$ & $5,8 \%$ & $8,3 \%$ \\
\hline Sin fotografía & $24,2 \%$ & $23,3 \%$ & $23,7 \%$ \\
\hline Sin relevancia & $3,6 \%$ & $2,1 \%$ & $2,8 \%$ \\
\hline Total general & $100,0 \%$ & $\mathbf{1 0 0 , 0 \%}$ & $\mathbf{1 0 0 , 0 \%}$ \\
\hline
\end{tabular}

Fuente: elaboración propia

Ambos medios de comunicación publican muchas fotografías, lo cual se constituye en un recurso para llenar páginas cuando el texto resulta reiterativo. Aunque también es cierto que se usan para, básicamente, mostrar los rostros de los protagonistas, como en Marca $(23,4 \%)$ y Mundo Deportivo (34\%,4\%) y mostrar las incidencias competitivas del partido (Marca, 23\% y Mundo Deportivo 22,9\%). Raras veces se muestran fotografías que apelen al conflicto entre las dos regiones que los clubes representan o, si lo hacen, lo hacen de manera sutil con el fondo de símbolos patrios al fondo de las jugadas del encuentro (Marca, 2,1\% y Mundo Deportivo, 0,7\%) y con los gestos del público con los jugadores emblemáticos de las dos escuadras, como se muestra en la portada de Marca del domingo, 3 de abril de 2016.

Vale anotar que las fotografías e infografías dotan a los dos diarios de un componente visual y estético destacado, usual en la prensa temática deportiva. 
Imagen 5

Fotografía en Marca

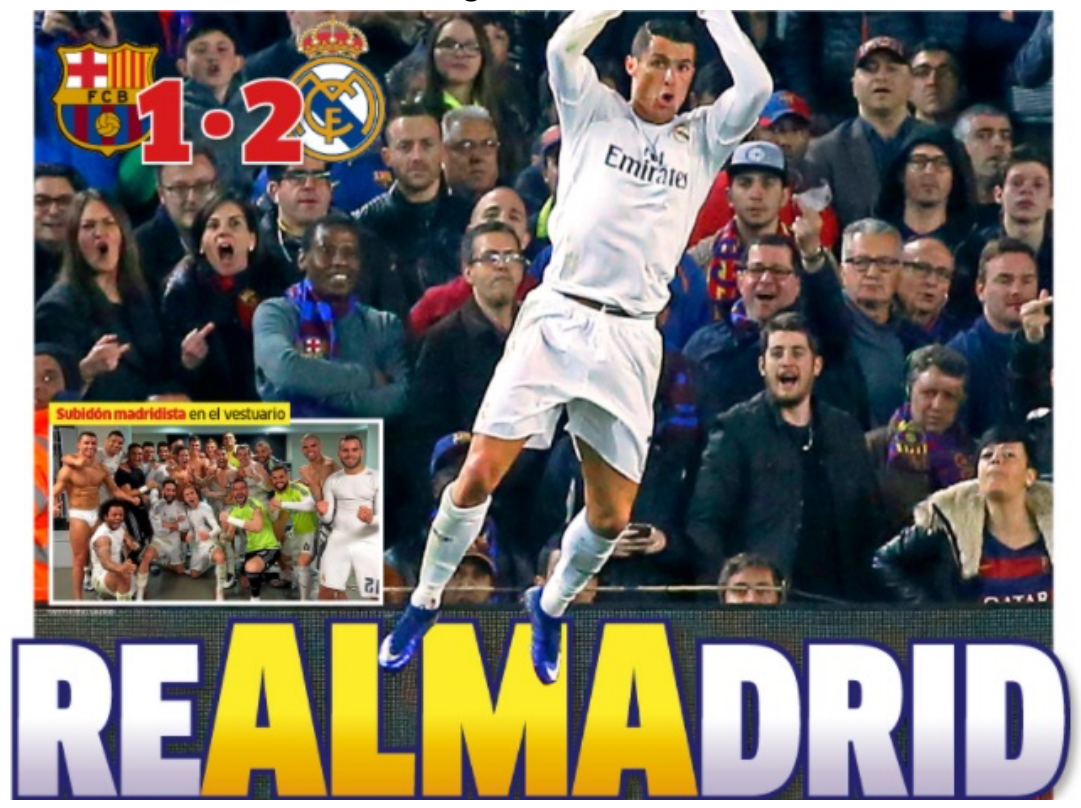

Figura 6

Infografía en el clásico del fútbol español en Marca y Mundo Deportivo

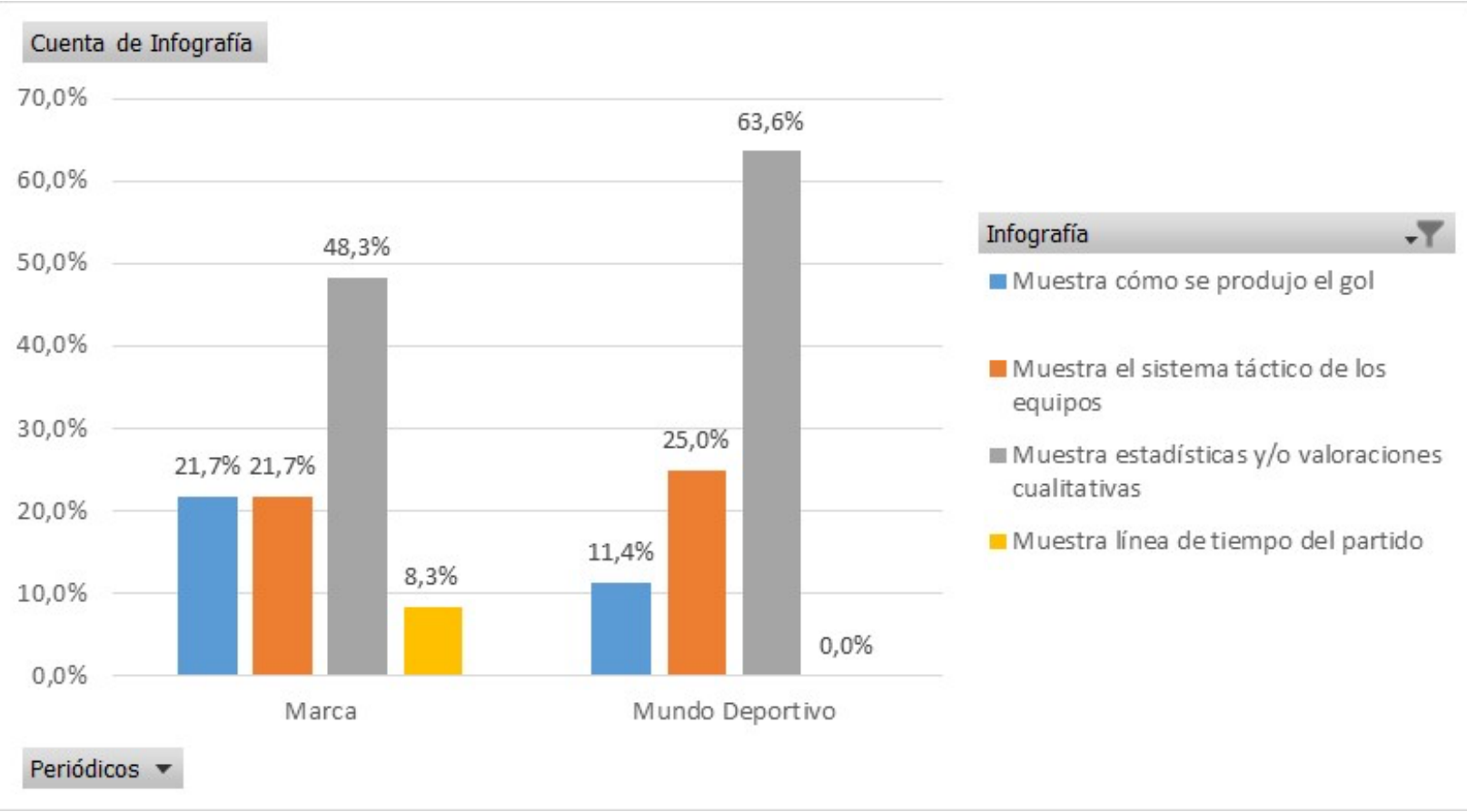

Fuente: elaboración propia

Se cuentan cuatro tipos de infografías, de las cuales tres usa Mundo Deportivo y las cuatro Marca. La que más se utiliza, en ambos casos, es la de mostrar estadísticas y o valoraciones cualitativas del equipo y los jugadores: Marca (48,3\%) y, con un significativo incremento, Mundo Deportivo (63,6\%). Marca sí publica la línea de tiempo del partido en un 8,3\% del total del recurso infográfico, mientras que Mundo Deportivo no lo hace. Los dos diarios también emplean infografías relacionadas con el sistema táctico de los equipos y la forma como se produjo el 
gol. Una de las infografías que combina las valoraciones cuantitativas y cualitativas, con las ubicaciones de las jugadas de gol es la que presenta Mundo Deportivo, del domingo, 26 de octubre de 2014, página 2.

\section{Imagen 6}

Infografía con valores cuantitativos

y cualitativos en Mundo Deportivo

2

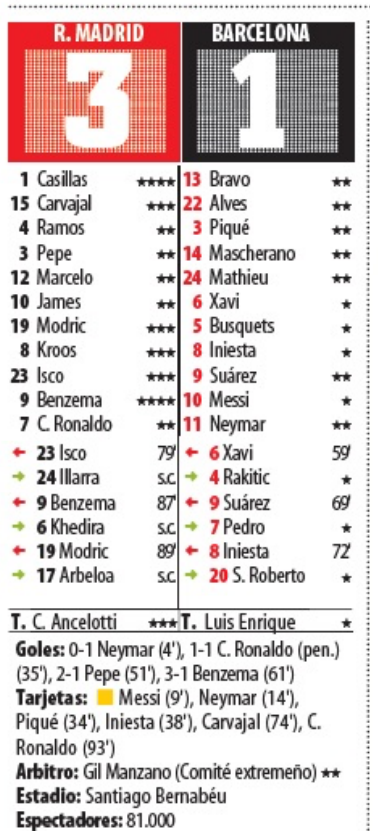

Espectadores: 81000
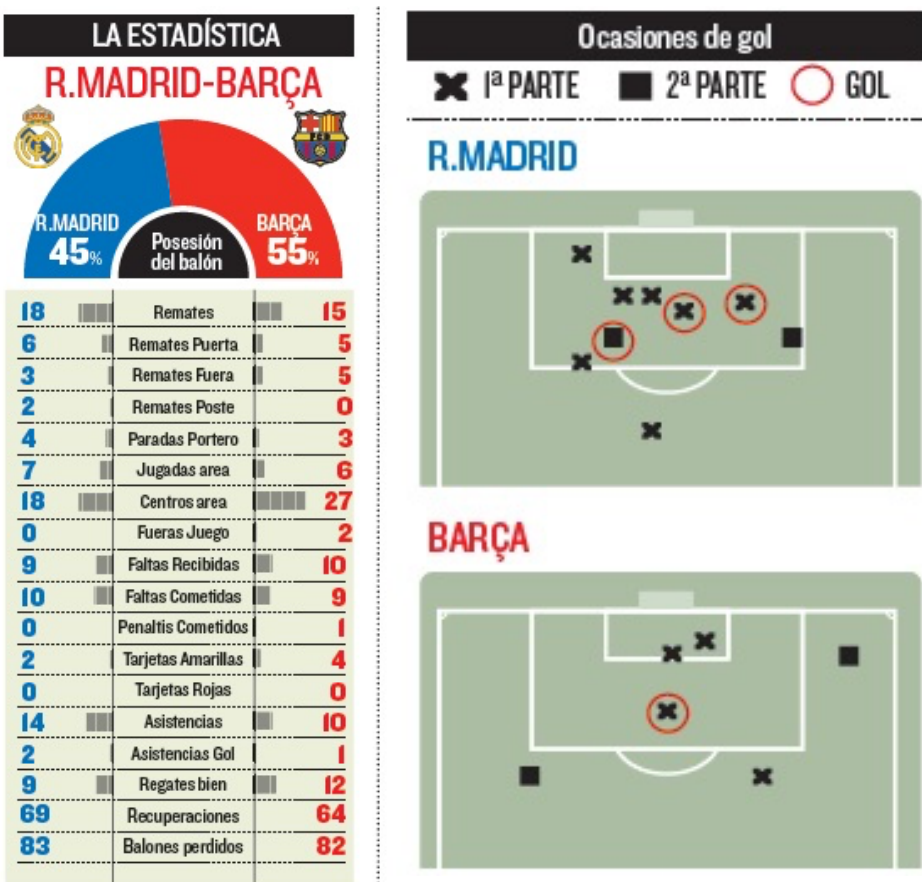

R.MADRID

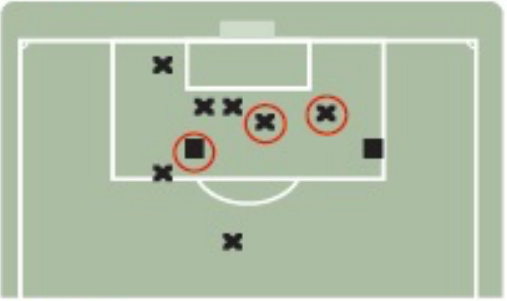

BARÇA

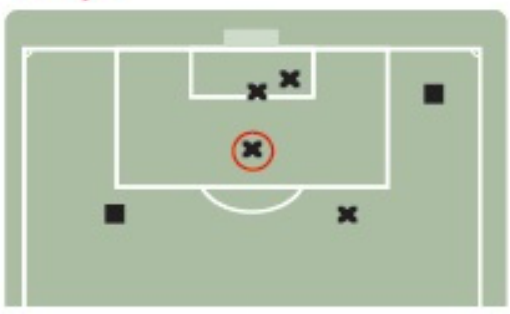

Figura 7

Fuentes del clásico del fútbol español en Marca y Mundo Deportivo

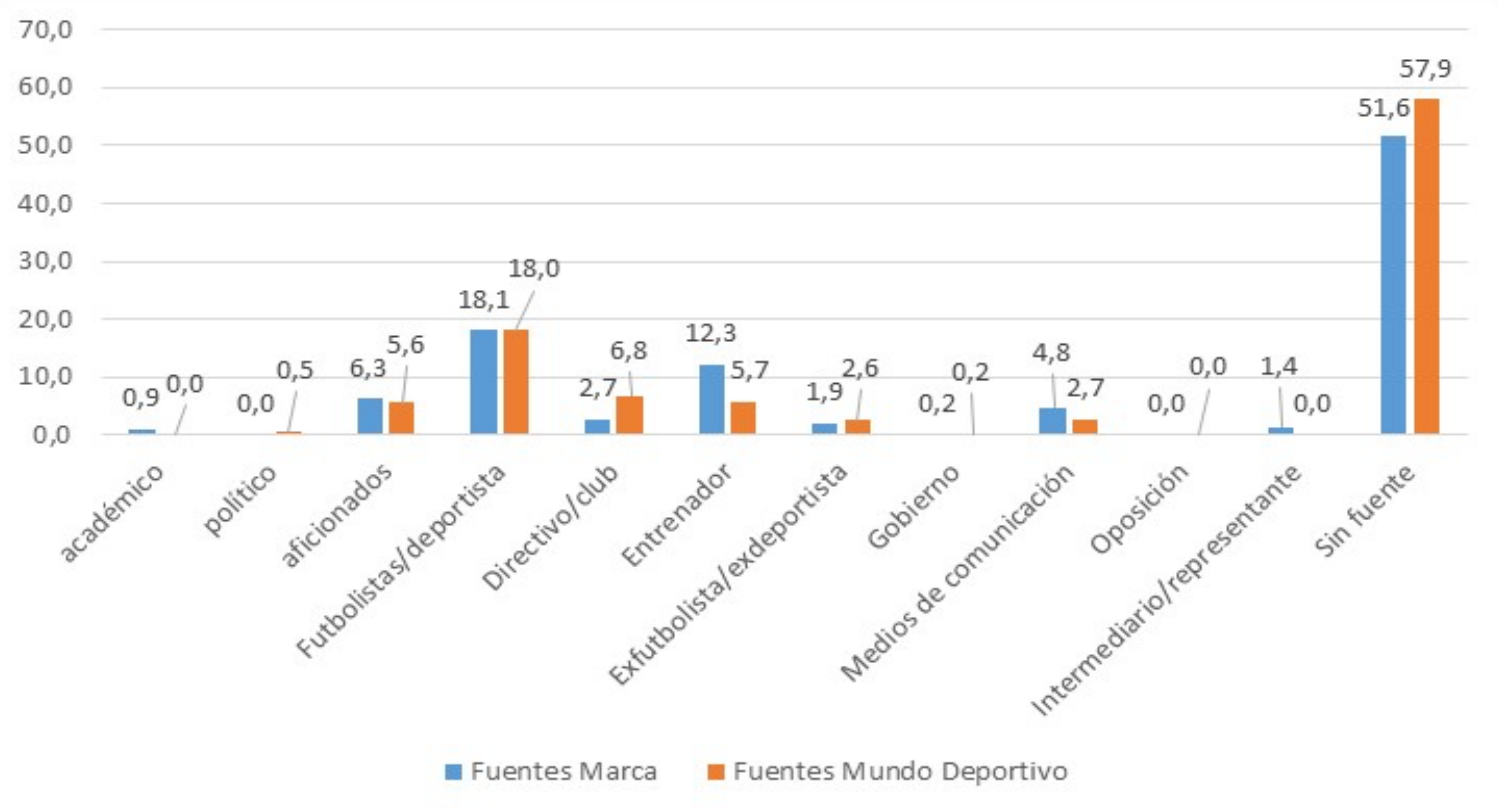

Fuente: elaboración propia 
Los dos diarios se caracterizan porque muchas de sus piezas periodísticas no tienen fuentes: Mundo Deportivo en un $57,9 \%$ y Marca en un 51,6\%. Como era de esperarse, las fuentes más consultadas son los futbolistas o deportistas: Marca 18,1\% y Mundo Deportivo 18\%. Los entrenadores son más consultados en Marca (12,3\%) que en Mundo Deportivo (5,7\%), pero este último medio de comunicación sí consulta a los políticos $(0,5 \%)$ sobre los resultados del clásico, en tanto que Marca no lo hace. A los académicos sí se les recoge una declaración sobre el partido y su resultado en Marca (0,9\%); en Mundo Deportivo, no. Marca publica más testimonios de los aficionados (6,3\%) que Mundo Deportivo (5,6\%).

\section{Cuadro 4}

Valor de los testimonios de las fuentes en Mundo Deportivo y Marca

\begin{tabular}{|c|c|c|c|c|c|c|c|c|c|c|c|c|}
\hline \multirow[b]{2}{*}{ Categoría } & \multicolumn{12}{|c|}{ Valores nominales de las fuentes del periódico Marca } \\
\hline & aca & pol & Afi & fud & dic & ent & efd & gob & $\mathrm{mcm}$ & opo & ire & Total \\
\hline Que apela a la confrontación & 1 & 0 & 3 & 27 & 2 & 6 & 0 & 0 & 1 & 0 & 1 & 41 \\
\hline Que refiere el desarrollo del partido & 9 & 0 & 66 & 156 & 16 & 115 & 22 & 1 & 54 & 0 & 15 & 454 \\
\hline $\begin{array}{l}\text { Que reivindica la identidad y cultura } \\
\text { regional/nacional }\end{array}$ & 0 & 0 & 0 & 4 & 2 & 2 & 0 & 0 & 0 & 0 & 0 & 8 \\
\hline Que reivindica la raza & 0 & 0 & 0 & 0 & 0 & 0 & 0 & 0 & 0 & 0 & 0 & 0 \\
\hline Que reivindica el territorio & 0 & 0 & 0 & 0 & 2 & 0 & 0 & 0 & 0 & 0 & 0 & 2 \\
\hline Que busca la convivencia y la reconciliación & 0 & 0 & 3 & 7 & 5 & 10 & 0 & 0 & 0 & 0 & 0 & 25 \\
\hline Que reivindica el valor del club & 0 & 0 & 0 & 14 & 4 & 8 & 0 & 1 & 0 & 0 & 0 & 27 \\
\hline \multirow[t]{2}{*}{ Total } & 10 & 0 & 72 & 208 & 31 & 141 & 22 & 2 & 55 & $\mathbf{0}$ & 16 & 557 \\
\hline & \multicolumn{12}{|c|}{ Valores nominales de las fuentes del periódico Mundo Deportivo } \\
\hline Categoría & aca & pol & Afi & fud & dic & ent & efd & gob & $\mathrm{mcm}$ & opo & ire & Total \\
\hline Que apela a la confrontación & 0 & 0 & 1 & 17 & 2 & 7 & 0 & 0 & 2 & 0 & 0 & 29 \\
\hline Que refiere el desarrollo del partido & 0 & 3 & 62 & 187 & 56 & 54 & 8 & 2 & 28 & 0 & 0 & 400 \\
\hline $\begin{array}{l}\text { Que reivindica la identidad y cultura } \\
\text { regional/nacional }\end{array}$ & 0 & 0 & 0 & 0 & 0 & 0 & 0 & 0 & 0 & 0 & 0 & 0 \\
\hline Que reivindica la raza & 0 & 0 & 0 & 0 & 0 & 1 & 0 & 0 & 0 & 0 & 0 & 1 \\
\hline Que reivindica el territorio & 0 & 0 & 0 & 0 & 0 & 0 & 0 & 0 & 0 & 0 & 0 & 0 \\
\hline Que busca la convivencia y la reconciliación & 0 & 3 & 2 & 0 & 13 & 2 & 22 & 0 & 0 & 0 & 0 & 42 \\
\hline Que reivindica el valor del club & 0 & 0 & 0 & 5 & 8 & 2 & 0 & 0 & 1 & 0 & 0 & 16 \\
\hline Total & 0 & 6 & 65 & 209 & 79 & 66 & 30 & 2 & 31 & 0 & 0 & 488 \\
\hline
\end{tabular}

Fuente: elaboración propia

En el periódico Marca, los testimonios que predominan son los que refieren el desarrollo del partido, como es habitual en la información deportiva. Los futbolistas expresan esta categoría en 156 ocasiones, seguidos de los entrenadores con 115 veces. En Mundo Deportivo, las declaraciones aumentan en los futbolistas y disminuyen en los entrenadores, así: 187 testimonios de los futbolistas refieren el desarrollo del partido y 54 testimonios de los entrenadores también lo hacen. Un valor significativo, aunque nominalmente menor, se registra en la categoría que apela a la confrontación. En efecto, en Marca los futbolistas se expresan así en 27 oportunidades y 6 en los entrenadores, mientras que en Mundo Deportivo la tendencia es 17 en los futbolistas y 7 en los entrenadores. Realmente, las otras fuentes, como aficionados, directivos, gobierno y oposición son poco consultadas, como ya hemos visto, poco intervienen con testimonios incendiarios o que apelan a la confrontación deportiva o política entre las regiones que ambos clubes representan. Vale anotar, igualmente, que los testimonios que apelan a la convivencia y la reconciliación son cuantitativamente relevantes, pero en este punto se destaca Mundo Deportivo con 42 declaraciones de esta naturaleza frente a los 25 de Marca. 


\section{Conclusiones}

El periodo analizado (temporada del 2003-2004 a la 2017-2018), demuestra que el número de piezas periodísticas varía en función del periódico y de su carácter nacional o regional. Es concreto, el número de informaciones sobre el clásico español es más alta en el diario Mundo Deportivo (966) que en Marca (889), pero no se debe exclusivamente a que en ese lapso de tiempo haya habido más triunfos del Barcelona sobre el Madrid, sino, a que Marca tiene un carácter más nacional e, incluso, internacional que Mundo Deportivo, por lo que debe dedicar espacio tanto al derbi como a otros deportes representativos de España o que sean de interés para una audiencia más amplia. Mundo Deportivo, con su carácter fundamentalmente regional, dedica más espacio al clásico de fútbol, puesto que su circulación está centrada en la comunidad autónoma de Cataluña, con algunas repercusiones nacionales y, escasamente, internacionales.

Según Alcoba (2010), los géneros más empleados para describir la performance atlética son la crónica (Marca 25,5\% y Mundo Deportivo 24,2\%) y la columna (Marca 14,7\% y Mundo Deportivo 14,6\%), debido a que permiten la emisión de juicios sobre los encuentros deportivos y sus protagonistas como una manera de canalizar la pasión de los aficionados y de los mismos reporteros. Sin embargo, observamos que en Mundo Deportivo y Marca son muy frecuentes las noticias (Mundo Deportivo 27,5\% y Marca 29,5\%), las cuales adquieren dos matices. El primero es que este género informativo trata de centrarse en la descripción de las acciones competitivas de los partidos, sin posturas identitarias personales, con lo cual se limitan las expresiones parcializadas o apasionadas de los periodistas. El segundo es que los hechos que se informan suelen ser repetitivos y reiterativos, a tal punto que el lector avezado podría concluir que tantas piezas periodísticas diciendo prácticamente lo mismo (el esquema táctico, quiénes intervinieron en los goles, etc.) podrían reemplazarse por nuevos enfoques del derbi o informaciones sobre otras disciplinas deportivas.

Añadir titulares apelativos (sensacionalistas) (Mundo Deportivo 24,7\% y Marca 26\%) a las crónicas, columnas, noticias y otros géneros periodísticos, supone un riesgo para los diarios, en la medida en que pueden alterar los ánimos de los aficionados y de las posturas políticas e ideológicas que defienden sus equipos y el carácter unitario nacional o independentista que ellos puedan llegar a representar. Las fotografías, no obstante, van por el camino contrario. Lo que los resultados indican es que son muy pocas las imágenes que explícita o simbólicamente muestran el enfrentamiento entre el Fútbol Club Barcelona y el Real Madrid, más allá de lo estrictamente deportivo, que puedan pasar al terreno de lo político e ideológico desde una mirada provocadora y belicista.

El enfoque de las piezas periodísticas versa, fundamentalmente, sobre el fútbol y la competencia (Marca 79,5\% y Mundo Deportivo 86,9\%), esto es, la descripción e interpretación de la actividad atlética, con el respectivo análisis de jugadas, decisiones arbitrales, sistemas tácticos, etc. También aparece un registro porcentual del enfoque del fútbol y confrontación (Marca 10,2\% y Mundo Deportivo 4,5\%) de baja intensidad, en el sentido de que hay acusaciones de escasa deportividad, parcialidades arbitrales, faltas alevosas entre los jugadores $y$ algunas referencias conflictivas a la identidad de lo que los clubes representan para sus territorios, pero no una postura clara y directa que motive el enfrentamiento entre los dirigentes y aficionados de los clubes, sobre la base de las diferencias históricas, políticas e ideológicas de catalanes y madridistas.

El lenguaje en las piezas periodísticas concuerda con el enfoque, es decir, el lenguaje está impregnado de jerga futbolística para describir el culmen competitivo (Mundo Deportivo 47,5\% y Marca 49\%), lo cual acrecienta la rivalidad de los equipos, sus fanáticos y regiones. Sin embargo, existen porcentajes significativos en los que se aprecia el lenguaje de la guerra (Marca 3,8\% y Mundo Deportivo 4,7\%), del aumento de las diferencias identitarias (Mundo Deportivo 1,4\% y Marca 2,4\%) y deportivas (Mundo Deportivo 7,8\% y Marca 9,3\%) entre el Barcelona Fútbol Club y el Real Madrid y los territorios que representan. 
Una tendencia de los periódicos temáticos deportivos es la falta de fuentes consultadas en su contenido (Marca 51,7\% y Mundo Deportivo 57,9\%), así se evidencia en Mundo Deportivo y Marca, lo cual los convierte en un tipo de periodismo liviano, especulativo, sin soportes, una sección de juguete como la denominan las otras especialidades periodísticas (Rowe, 2007). Aun así, las fuentes que más se consultan en los dos diarios son, lógicamente, los jugadores de fútbol, aunque una distinción notoria entre Marca y Mundo Deportivo estriba en que el primero ofrece testimonios de académicos (Marca 0,9\% y Mundo Deportivo 0\%) y el segundo ofrece declaraciones de políticos (Mundo Deportivo 0,9\% y Marca 0\%) sobre el derbi del fútbol español. Ahora bien, al referirnos al tipo de testimonio de las fuentes, ambos medios de comunicación dan prioridad a las incidencias competitivas del partido (Mundo Deportivo 454 y Marca 400), pero también aparecen valores nominales algo significativos referidos a la confrontación entre los equipos, principalmente en Marca (41 y Mundo Deportivo 29). Mundo Deportivo (42) publica declaraciones de los protagonistas más en sintonía con la reconciliación y la convivencia que Marca (25).

Un aspecto relevante de los dos diarios es, sin duda, sus avances en la presentación gráfica de los contenidos, lo cual va en línea con una de las fortalezas del periodismo deportivo (Rojas, 2011). Las infografías son su mejor ejemplo, pues, por una parte, tratan de darle un cariz racional $y$, a veces, predictivo al performance atlético mediante la exposición de estadísticas, mapas de calor, valoraciones cuantitativas y cualitativas y fotomontajes, copiando, en gran parte, el enfoque funcionalista que los estadounidenses dan a sus deportes, como el béisbol (frecuencia de bateo, bases robadas, etc.). Por otra, mejoran la visualización de los contenidos, apelando a las nuevas técnicas que provee el periodismo de datos, con lo cual se atrae a públicos diversos.

Una vez revisado e interpretado estos datos, consideramos que el frame (encuadre) predominante en las piezas periodísticas de Marca y Mundo Deportivo tiene estas características: (1) aunque los contenidos de los dos medios priorizan la actividad atlética y competitiva, asimismo se valen de un lenguaje bélico y confrontador de baja intensidad para aumentar las diferencias deportivas, culturales e identitarias de los dos equipos y las regiones que representan, así como de las ideologías que subyacen en torno a los deseos unionistas o independentistas; (2) existen momentos reconciliatorios cuando se informa de las comidas y cenas de los presidentes de los clubes antes del partido, así como de los gestos de amistad de sus peñas (barras), pero el énfasis está dado en la rivalidad para mantener vigentes las diferencias políticas e ideológicas y, de paso, incrementar la venta de los periódicos, apelando a los debates que surgen de cualquier encuentro futbolístico: fallas arbitrales, acusaciones de falta de deportividad, referencias históricas que benefician o perjudican a los clubes, y la publicación de testimonios explosivos de los protagonistas del clásicos que incentivan la división y las pasiones de los aficionados; (3) los dos diarios destacan por la propiedad con que usan los recursos gráficos y el periodismo de precisión (análisis de variables cuantitativas y cualitativas de los partidos), para mejorar la visualización de los contenidos y, por ende, atraer la atención de los lectores, lo cual, además, busca darle un matiz racional, casi científico al desempeño atlético, y no simplemente pasional como lo manifiestan, con sorna, algunos públicos académicos; (4) las diferencias en los dos periódicos no son significativas en el enfoque y lenguaje de las informaciones: en Marca es más evidente la preocupación por el diseño visual, con más opciones de infografías, y una propensión un tanto mayor a aprovechar la confrontación y las expresiones beligerantes, mientras que en Mundo Deportivo es prolífico en el número de informaciones sobre el derbi, sobre todo porque en el periodo estudiado fueron más los triunfos del Barcelona, con alusiones esporádicas a la identidad catalana, y con un lenguaje y enfoque que por momentos apela a la reconciliación, situación que puede contrastar con la forma como se muestra el conflicto madridista y catalán en los medios de comunicación generalistas desde la perspectiva histórica, política e ideológica.

Esta investigación determina que, pese a que el nivel de confrontación que presentan Mundo Deportivo y Marca es de baja intensidad, los dos periódicos incentivan la polarización política e ideológica, como ya lo diagnosticaron Barredo y Oller (2017). No obstante, no es descabellado pensar que si las condiciones políticas y 
socioeconómicas cambian desfavorablemente en España, como puede ocurrir en cualquier país, el nivel de conflicto puede aumentar, situación que puede estar atizada por un lenguaje deportivo que no mida las consecuencia de incentivar la división y el enfrentamiento entre hinchadas, directivos, clubes y colectivos partidistas, mediante piezas periodísticas que no filtran expresiones bélicas ni testimonios fuera de tono que denigran o desprestigian al rival y al territorio que representan. De ahí la necesidad de que los dos medios de comunicación activen protocolos éticos para que sus periodistas informen adecuadamente sobre el deporte y sus vínculos con el nacionalismo, la política y la identidad.

\section{Referencias bibliográficas}

Alcoba, A. (2010). Periodismo deportivo. Madrid: Síntesis.

Billings, A. (2010). La comunicación en el deporte. Clemson University, USA: Editorial UOC.

Billings, A. C., Butterworth, M. L. \& Turman, P. D. (2012). Communication and Sport. Surveying the field. California, USA: Sage Publications, Inc.

Barredo, D., \& Oller, M. (2017). La polarización de la información deportiva: Análisis de los titulares en MARCA.com y SPORT.es en los enfrentamientos entre Real Madrid C. F. y F. C. Barcelona (2010-11). TecCom Studies, Estudios de Tecnología y Comunicación, 1(April), 26-34.

https://www.researchgate.net/publication/262871268_El_periodista_frente_a_la_crisis_del_periodismo_ en_la_era_digital

Bryman, A., \& Teevan, J. (2005). Social Research Methods. Canadian Edition. Toronto: Oxford University Press.

Colomé, G. (199). Conflictos e identidades en Cataluña. En Segurola, Santiago (ed.). Fútbol y pasiones políticas. Barcelona: Debate, 169-174.

González, M. E. (2014). Prensa deportiva e identidad nacional : España en el Mundial de fútbol de Sudáfrica 2010. Politica y Sociedad, 54(2), 337-366. https://revistas.ucm.es/index.php/POSO/article/view/43077

Hernández, Roberto; Fernández, Carlos y Baptista, P. (2014). Metodología de la investigación (6a. Edición). México D.F.: McGraw Hill. https://doi.org/10.1192/bjp.112.483.211-a

Holsti, O. (1969). Content Analysis for the Social Sciences and Humanities, Reading (Massachussets, EE. UU.): Addison-Wesley.

Igartua, J. J. (2006). Métodos cuantitativos de investigación en comunicación. Barcelona: Bosch comunicación.

Igartua, J. J., \& Humanes, M. L. (2010). Teoría e investigación en comunicación social. Madrid: Síntesis.

Kassing, J., Billings, A., Brown, R., Halone, K., Harrison, K., Krizek, B., \& Mean, L. (2004). Communication in the Community of Sport. Communication Yearbook, 373-409.

Kiosco.net (2020). Prensa deportiva de España. https://es.kiosko.net/es/sport.html

Leone, A. (2019). Barça-Madrid: un partido con una audiencia mundial de 650 millones de espectadores. https://elpais.com/deportes/2019/10/17/actualidad/1571326299_016298.html

Llopis, R. (2016). Deporte, medios de comunicación y sociedad. Revista Internacional de Ciencias del Deporte, 12(44), pp. 86-89. Recuperado de http://goo.gl/qsH7Af

López, A. (2009). El titular. Manual de titulación periodística. Sevilla, España: Alfaomega. 
McQuail, D. (2000). Introducción a la teoría de la comunicación de masas (3a. Edició). Barcelona: Paidós.

Pinheiro, F. (2012). Desporto o media como objecto de investigaçao. En Marín, J. (Coord.). Deporte, comunicación y cultura, 21-53. Salamanca: Comunicación Social, Ediciones y Publicaciones.

Rojas, J. L. (2011). Periodismo deportivo de calidad. Propuesta de un modelo de libro de estilo panhispánico para informadores deportivos. Madrid: Fragua.

Rojas, J.L. (5 de febrero de 2015). La prensa deportiva en España. (L. Angulo, entrevistador).

Rowe, D. (2007). Sports journalism. Still the 'toy department' of the news media? Journalism,

Vol. 8, Issue 4, pp. 385-405.

Rubio, J. (2009). Opinión pública y medios de comunicación. Teoría de la agenda setting. Gazeta de Antropología, 25(25), 1-17.

Schutt, R. K. (2019). Investigating the Social World: the Process and the Practice of Research. In Journal of Chemical Information and Modeling (Ninth, Vol. 53, Issue 9). California, USA: Sage.

Suárez, O. (2015). Los cuerpos del poder. Deporte, política y cultura. Barcelona: Córner/Libros del Atril.

Wimmer, R., \& Dominick, J. (1996). La investigación científica de los medios de comunicación. Una introducción a sus métodos. Barcelona: Bosch. 